\title{
Relato sobre internação hospitalar para procedimento cardiológico no início da pandemia de Covid-19
}

\author{
Report on hospitalization for cardiological \\ procedures at the beginning of the Covid-19 \\ pandemic
}

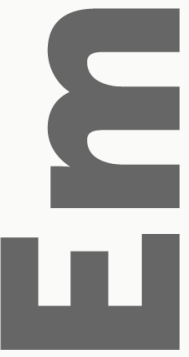

\section{RESUMO}

O presente texto relata a experiência da autora durante internação hospitalar para intervenção cardiológica, em março de 2020, quando teve início a pandemia do Covid-19. Por ser médica e antropóloga, ela observou as condutas dos profissionais do setor, no que concerne ao uso de máscaras e cuidados em relação ao coronavírus. $O$ barulho na unidade hospitalar e a manutenção da consciência da paciente internada constituíram objeto de incômodo, respectivamente, para a autora e para a equipe de saúde. O relato aborda as dificuldades de adaptação de profissionais de saúde a novas situações, como as diretivas antecipadas de vontade; além dos desafios de lidar com doente lúcido e com capacidade de exercício de livre arbítrio.

Palavras-chave: Internação hospitalar - Livre arbítrio - Diretivas Antecipadas de Vontade - Pandemia - Coronavírus

\begin{abstract}
This text reports the author's experience during hospitalization for cardiological intervention, in March 2020, when the Covid-19 pandemic began. As a doctor and anthropologist, she observed the conduct of professionals in the sector, with regard to the use of masks and care in relation to the coronavirus. The noise in the hospital unit and the maintenance of the inpatient's consciousness were an object of discomfort, respectively, for the author and for the health team. The report addresses the difficulties of adapting health professionals to new situations, such as anticipated directives of will; in addition to the challenges of dealing with a lucid patient and with the ability to exercise free will.
\end{abstract}

Keywords: Hospitalization - Free will - Anticipated Directives of Will Pandemic - Coronavirus

* Doutora em Saúde Coletiva pelo Instituto de Medicina Social da Universidade do Estado do Rio de Janeiro (UERJ). Professora Associada do Instituto de Estudos em Saúde Coletiva da Universidade Federal do Rio de Janeiro (IESC/UFRJ) e do Programa de Pós-Graduação em Saúde Coletiva do IESC/UFRJ. CV: http://lattes. cnpq.br/3860753416382806 
Sou médica e antropóloga. Em 2011, ao descobrir a existência de um Foramen Oval Patente (FOP), tive contato com muitos cardiologistas (sobretudo com professores de cardiologia de renome, titulares e associados de universidades públicas do Rio de Janeiro e de São Paulo), para ouvir seus pareceres. O FOP significa a existência de uma passagem entre átrios direito e esquerdo, áreas que usualmente não se comunicam, uma má formação congênita. Na ocasião, as opiniões convergiram: a indicação de oclusão era restrita a pessoas com até, no máximo, 45 anos - idade menor do que a minha. Portanto, à época, as recomendações eram no sentido do uso de medicamentos, exercícios e acompanhamento médico para controle da lesão.

Em 2017/2018 foram publicados dois grandes estudos multinacionais europeus sobre procedimento para FOP, recomendando fortemente a oclusão por cateterismo cardíaco, sem definição de qualquer limite de idade. À época conversei com diferentes médicos, recebi opiniões as mais diversas. Decidi então por não realizar a intervenção. Contudo, em 2020, com a descoberta de um nódulo na mama, deveria ser submetida a uma cirurgia para sua retirada. Segundo os médicos então consultados - cardiologista, mastologista, oncologista a recomendação foi de primeiro efetuar o fechamento da passagem no coração. De acordo com o profissional especializado, a intervenção era simples, com internação hospitalar de, no máximo, 24 horas. Como a oclusão era condição para a cirurgia da mama, decidi marcar o procedimento cardiológico.

Em 24 de março de 2020, início da pandemia, fui internada em hospital privado da zona sul da cidade do Rio de Janeiro, com o objetivo de ser submetida a um cateterismo, para oclusão do FOP. No Brasil, a orientação do Ministério da Saúde seguia as diretivas da Organização Mundial de Saúde: afastamento social, com utilização de máscaras, luvas, cuidados nos contatos e, sobretudo, uso de álcool gel. Em todos os setores para admissão no hospital havia álcool gel disponível. Contudo, muitos funcionários trabalhavam sem máscaras, poucos com luvas. À época, o uso de máscaras não era regido por lei. Após os procedimentos burocráticos, fui conduzida para um "box" na unidade cardíaca. Estava acompanhado por meu marido. O espaço que ocupava era menor que um quarto, contava com aparelhagem para monitoramento do paciente (como passei a ser identificada pela equipe), um sofá-cama, uma poltrona e um banheiro privativo. Ao ser internada, preenchi formulário com meus dados, histórico com doenças pregressas, alergias e outras informações.

No box, alguns profissionais vieram me examinar e solicitar informações sobre o histórico médico. As perguntas se repetiam: a senhora é diabética? É hipertensa?

Estes e outros dados foram registrados nos formulários que preenchi na recepção, ao ser internada. Todos os profissionais (enfermeira, técnica de enfermagem, nutricionista, médico do plantão, anestesista) que indagaram estas questões tiveram acesso ao formulário preenchido e, aparentemente, não leram as respostas. Quando indaguei a razão de repetirem as perguntas, soube que é um protocolo para certificação da veracidade dos dados. Certamente o fato de ser idosa consistiu em referência para as indagações e avaliação das respostas.

Entreguei uma cópia impressa de minha diretiva antecipada de vontade (DAV) assinada ao anestesiologista, uma vez que somente teria contato com o cardiologista intervencionista 
no Centro Cirúrgico. A DAV é um documento no qual são expressas as vontades da pessoa, no que concerne a cuidados e tratamentos que deseja, no momento em que estiver incapacitada de expressão da própria vontade. O anestesista guardou o documento após leitura do título, sem ler o texto. A maioria dos profissionais que entrava no box para avaliação de meus sinais vitais, obtenção de dados e preenchimento de formulários não utilizava máscara nem luvas, à exceção do anestesista e da nutricionista, que usavam máscaras. Na estante localizada na entrada do box havia uma caixa com luvas, outra com máscaras e um frasco com álcool gel este era o mais usado. A nutricionista fez as perguntas na porta do recinto, parecia ter receio de entrar. Como falo em tom de voz baixo, várias vezes precisei repetir minha resposta, pois ela não escutava: com a porta aberta do box, havia ruídos provenientes dos outros boxes e dos profissionais de limpeza que transitavam com seus equipamentos.

Meu espaço era no final do corredor, de modo que para sair do setor necessariamente passava por todos os boxes anteriores e por um quadro na parede do corredor, que continha o número dos boxes, as iniciais dos pacientes ali internados, suas idades, diagnósticos e indicações dos procedimentos. Pelo fato de ser médica, tenho conhecimento das principais siglas das enfermidades e intervenções cardiológicas. Ao ler o quadro constatei que a maioria dos doentes era constituída por pessoas muito idosas, com quadros cardiológicos graves. Muitos estavam sedados e alguns entubados, sem possibilidade de comunicação, eu era uma das poucas pessoas ali internadas com capacidade de diálogo e de exercício de livre arbítrio.

Fui conduzida ao Centro Cirúrgico em maca, como manda o protocolo, apesar de estar em condições de andar. Ali, mais uma vez recebi as mesmas indagações: diabética? hipertensa? Cada vez que respondia, reiterava que já havia afirmado para outros profissionais os mesmos dados. Em dado momento, questionei a obrigatoriedade de leitura das papeletas - de enfermagem, médicos, nutrição. Os profissionais reiteravam que estavam seguindo o protocolo.

Após o procedimento, acordei neste setor com a notícia de que tudo correu bem. Ao retornar ao box, notei que as técnicas de enfermagem não usavam máscara. No corredor havia funcionários da equipe de limpeza sem máscaras. No retorno ao box, após o procedimento, fui monitorizada. Para tanto, uma técnica de enfermagem posicionava os eletrodos (para eletrocardiograma), enquanto eu conversava no celular, dando notícia do procedimento. Subitamente dei um grito, ao sentir um forte beliscão na mama direita. A profissional havia colocado o eletrodo no local errado. Reclamei, solicitei que ela saísse do quarto e chamei imediatamente a enfermeira responsável pelo setor. A enfermeira pediu muitas desculpas, afastou a técnica de enfermagem desatenta e designou outra profissional, mais graduada, para me assistir.

Fiquei internada por pouco mais de um dia. Não tenho dúvidas de que a equipe de enfermagem recebeu orientações de sua chefia para o contato com a paciente médica, professora da UFRJ, pois diversas profissionais entravam no box com indagações sobre minhas atividades profissionais. Contudo, provavelmente também fiquei conhecida como a paciente que reclamava, em função do ocorrido na única noite em que dormi no hospital. Nesta noite, o posto de enfermagem foi local de encontro e de papo entre os plantonistas das diferentes 
categorias profissionais. As risadas eram em tom de voz alto, as piadas e os casos eram contados com entusiasmo. É possível que os outros doentes internados não se queixassem, pois estavam entubados e sedados - o que, felizmente, não era meu caso - de modo que meu marido e eu reiteradamente solicitamos que as conversas fossem em tom de voz mais baixo, o que ocorria por dez minutos. No entanto, em pouco tempo as risadas se tornavam mais altas. A reunião social foi encerrada após uma hora da madrugada - quando meu marido solicitou, pela enésima vez, que reduzissem o volume do som nas conversas.

No segundo dia de internação recebi a orientação médica de me levantar e andar. Caminhei então pelos corredores do setor. Ali encontrei muitos profissionais sem máscaras, conversando, sobretudo no posto de enfermagem. Em determinado momento cruzei com três profissionais de limpeza, parados. Uma estava sem máscaras nem luvas, enquanto os outros dois usavam máscaras e luvas para limpeza. O assunto era a pandemia. Um funcionário afirmou então que achava que era tudo exagero, que ia passar logo, que o "povo acreditava em chineses", que inventaram esta "tal de epidemia". Ele ria e afirmava que não ia ficar de máscara. Dirigi-me então ao grupo, explicando que não era exagero, que havia de fato uma epidemia, que eles eram profissionais em contato com doentes, corriam alto risco de contágio, razão pela qual deviam se cuidar. Identifiquei-me como médica, disse que ali, naquele hospital estava sendo organizada uma UTI para internação de casos graves de infectados por covid-19 (informação transmitida pela enfermeira chefe da unidade, que era responsável pela organização do novo setor), e que o atendimento de emergência já estava recebendo muitos contaminados. Os profissionais da limpeza escutaram, agradeceram as notícias e disseram que iam se cuidar. Mais adiante, quando estava no box, escutei um deles afirmar que "aquela médica é exagerada, não é bem assim".

O diálogo ocorreu no dia 25 de março de 2020. De lá para cá morreram muitos brasileiros por covid (no momento em que escrevo o número oficial de óbitos ultrapassa 170 mil) ${ }^{1}$ e, também, por outras causas - talvez por falta de atendimento a outras patologias, por impossibilidade de cirurgias e/ou tratamentos, uma vez que o foco passou a ser centrado no combate ao coronavírus.

Este relato aponta temas a serem aprofundados, como as dificuldades de mudanças e adaptação de atitudes sociais, em face de novas situações. Em pouco tempo, a epidemia se tornou uma realidade para todos os brasileiros, inclusive para aqueles funcionários da limpeza do hospital. É de estranhar sua resistência a utilizar equipamento de proteção individual, sobretudo por se tratar de pessoas com atividade laboral em instituição hospitalar - terceirizados ou funcionários daquela unidade.

Restam muitas indagações, mas não tenho dúvidas de que a sensibilização de equipes de saúde é imprescindível em nosso país - seja no que concerne a alterações de protocolos, de condutas, no exame dos próprios preconceitos, como os de idade, raça, religião, orientação sexual, entre tantos outros, capazes de afetar o cuidado com a saúde. A expressão de meus desejos na Diretiva Antecipada de Vontade foi de extrema relevância para mim, assim como

1 Número de mortos por ocasião da redação desse relato. Vale mencionar que, em maio de 2021, o número oficial de mortos por covid-19 no Brasil alcançou o montante de 440 mil. 
a desqualificação do documento pelos colegas que o receberam foi indício marcante de sua rejeição ao diálogo em torno de qualquer eventualidade clínica ou cirúrgica (que felizmente não ocorreu) que impossibilitasse minha tomada de decisões.

Em 25 de março de 2020, deveria receber alta da internação após avaliação do cardiologista de plantão no setor. Como estava bem e o médico não vinha ao box, caminhando pelos corredores do setor, dirigi-me ao posto de enfermagem e à sala de médicos, em busca do plantonista. Encontrei a enfermeira chefe, e solicitei então que ela se comunicasse com ele, para autorizar minha alta. A enfermeira transmitiu ao cardiologista os parâmetros de minhas funções vitais, e minha alta hospitalar foi assinada pelo plantonista. A saída do hospital marcou a recuperação de minha identidade, pois no pouco tempo de internação fui transformada: de uma médica e professora universitária, lúcida e orientada, em uma idosa que deve ser inquirida para verificação de suas capacidades.

O surgimento da pandemia do novo coronavírus, com um número significativo de óbitos ocorridos em situação de isolamento social, como em UTIS, também apontou para a centralidade e importância da atenção ao último período de vida de enfermos graves, bem como para os rituais após a morte e o luto vivenciado por familiares. No século XXI, cada vez mais assistimos ao surgimento de modalidades inovadoras de assistência ao morrer e à expansão de diálogo em torno do final da vida e da morte. De certo modo, o advento da pandemia atravessa e impulsiona os movimentos em torno da crescente visibilização e aceitação do morrer. Nessa direção, é premente a criação de espaços para debates e trocas - entre profissionais de saúde e a sociedade em sentido amplo, acerca das formas de exercício de livre arbítrio do doente, da gestão do morrer, dos cuidados após o falecimento, dos rituais e do luto.

Recebido em: 07 de janeiro de 2021

Aprovado em: 23 de fevereiro de 2021 